\title{
An analysis of the influence of logistics activities on the export cold chain of temperature sensitive fruit through the Port of Cape Town
}

\author{
Authors: \\ Leila L. Goedhals-Gerber ${ }^{1}$ \\ Laura Haasbroek ${ }^{1}$ \\ Heinrich Freiboth ${ }^{1}$ \\ F. Esbeth van Dyk ${ }^{2}$ \\ Affiliations: \\ ${ }^{1}$ Department of Logistics, \\ Stellenbosch University, \\ South Africa \\ ${ }^{2}$ Council for Scientific and \\ Industrial Research, Built \\ Environment, South Africa

\section{Correspondence to:} \\ Leila Goedhals-Gerber

\section{Email:} \\ leila@sun.ac.za

\section{Postal address:} \\ Private Bag X1, Matieland \\ 7602, South Africa

\section{Dates:} \\ Received: 06 July 2015 \\ Accepted: 13 Aug. 2015 \\ Published: 30 Sept. 2015 \\ How to cite this article: \\ Goedhals-Gerber, L.L., \\ Haasbroek, L., Freiboth, H. \& \\ Van Dyk, F.E., 2015, 'An \\ analysis of the influence \\ of logistics activities on \\ the export cold chain of \\ temperature sensitive \\ fruit through the Port of \\ Cape Town', Journal of \\ Transport and Supply Chain \\ Management 9(1), Art. \\ \#201, 9 pages. http://dx.doi. \\ org/10.4102/jtscm.v9i1.201

\section{Copyright:} \\ (C) 2015. The Authors. \\ Licensee: AOSIS \\ OpenJournals. This work is \\ licensed under the Creative \\ Commons Attribution \\ License.
}

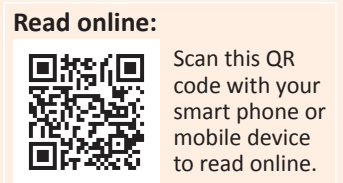

Background: South Africa exports a large variety of different fruit types and cultivars worldwide. Yet, there is concern in the South African fruit industry that too much fruit and money is lost each year due to breaks along the fresh fruit export cold chain.

Objective: The objective of this article was to identify the influence of logistics activities on breaks along the South African fruit export cold chain. The focus is specifically on temperature sensitive fruit, exported in refrigerated containers to Europe and the United Kingdom through the Port of Cape Town. This supply chain was selected as this was the most accessible supply chain in terms of retrieving the necessary temperature data.

Method: The cold chain was investigated from the cold store, through all segments, until the Port of Cape Town. Temperature data collected with temperature monitoring devices from different fruit export supply chains of grapes, plums and pome fruit (apples and pears) were analysed to identify the percentage of temperature breaks and the length of temperature breaks that occur at each segment of the cold chain.

Results: The results show that a large number of breaks are experienced along South Africa's fruit export cold chain, specifically at the interface between the cold store and the truck. In addition, the findings also show that there has been an improvement in the number of breaks experienced in the Port of Cape Town following the implementation of the NAVIS and Refcon systems.

Conclusion: This article concludes by providing the fruit industry with areas that require addressing to improve operational procedures along the fruit export cold chain to help ensure that the fruit arrives at its final destination at optimal quality.

\section{Introduction}

Fruit exports account for $50 \%$ of all agricultural exports in South Africa, with an export value of approximately R19.8 billion during 2013 (A. Kruger, Fresh Produce Exporters' Forum CEO, pers. comm., 2014). It is a significant employment generator, employing approximately 460000 people with approximately 2 million dependents (Kruger, Fresh Produce Exporters' Forum CEO, pers. comm., 2014). Yet, there is a concern in the South African fruit industry that a large amount of fruit and money is lost every season (Postharvest Innovation Programme 2013). This is thought by industry experts to be mainly due to a loss of fruit quality as a result of breaks in the cold chain. According to research conducted by Hill \& Waller (quoted in Ogunleye \& Adefemi 2007) postharvest losses are approximately $10 \%-20 \%$ worldwide. This is similar to the findings of Aiello, La Scalia and Micale (2012), who estimate that approximately $12 \%$ of fresh produce in developed countries is lost and the findings of the Food and Agriculture Organization of the United Nations (2011), who state that postharvest losses range between 10\% and 15\%. Even if postharvest losses are as low as 10\%, the result is still a R1.98 billion loss in terms of 2013 fruit exports.

The most important factor in postharvest management is temperature management (Jobling 2002). Even small variations in temperature can significantly impact the shelf life of fresh produce and its value (Intelliflex 2012). Therefore, any break in the cold chain at any stage along the supply chain will result in a reduction of shelf life. The longer the cold chain is broken, the greater the impact will be on the shelf life of the fruit. In addition, numerous short breaks in the cold chain can be as detrimental to the shelf life of the fruit as one long break (M. Dodd, pers. comm., 13 July 2013).

Technology used in the transportation and storage of fruit has developed over time. In 1980, $33 \%$ of refrigerated maritime transport capacity was containerised. The remainder of the capacity was handled by conventional reefer ships, with the capacity of a typical conventional vessel 
approximately 4500 pallets and larger vessels carrying up to 6000 pallets at a time. The percentage of refrigerated containerised transport increased to $90 \%$ in 2010 (M. Dodd, pers. comm., 13 July 2013). The increase in the use of containers for the export of fruit has resulted in the need to rethink and redesign the packaging of fruit, as incorrect airflow through the fruit has been shown to affect the quality and shelf life of the fruit (M. Dodd, pers. comm., 13 July 2013). There is a misconception that the refrigeration units inside the reefer containers have the ability to cool fruit down below required protocols. However, reefer containers are designed to maintain the temperature within a predetermined range, not to cool it down. This implies that the cargo (in this case summer fruit) must be brought to the required temperature before being loaded into a reefer container (Perishable Products Exports Control Board [PPECB] 2013).

Additional changes that have been made to the fruit export supply chain in recent years include the implementation of the terminal operating system known as the Synchronous Planning and Real-time Control System (SPARCS) developed by NAVIS (hereafter referred to as the NAVIS system for the remainder of the article) and the Reefer Container Monitoring System, known as the Refcon system, at the Port of Cape Town. The NAVIS SPARCS is a Web-based terminal operating system used to monitor container movements along land transport routes and container movements and operations in the Port of Cape Town. The Refcon reefer monitoring system is a computer program which allows complete visibility of the status of reefer containers in the stack yard of a port. There is a perception in the fruit industry that the majority of the breaks in the fruit export cold chain originate in the Port of Cape Town (Postharvest Innovation Programme 2013). It is important to highlight that improvements have been made in the operational efficiency in the Port of Cape Town as a result of the implementation of the NAVIS and Refcon systems.

This article describes data that was collected during the summer fruit seasons of 2011/2012 and 2012/2013 (before and after implementation of the NAVIS and Refcon systems). It analyses ambient temperature data that was collected from loggers that were inserted into a carton of fruit - usually in the pallet closest to the door - just before the container was sealed. The temperature data was obtained through trials and from exporters. The article also determines whether the implementation of the NAVIS and Refcon systems in the Port of Cape Town made any difference to the number of breaks experienced in the fruit export cold chain. This article identifies the number and length of temperature breaks along the fruit export cold chain and provides industry with areas to focus on to improve operational procedures along the fruit export supply chain to ensure optimal quality.

The next section provides a literature review on the deciduous fruit industry and the challenges facing the deciduous fruit industry as a whole. It provides guidelines set out by the PPECB that are put in place to help ensure the best possible fruit quality and it gives an overview of the NAVIS and
Refcon systems. Data on the ambient temperature inside the containers as well as the number and length of breaks in the cold chain were collected during the summer fruit seasons, from November to the end of April, of 2011/2012 and $2012 / 2013$ from the point in the supply chain when the fruit was loaded into the containers until they were loaded onto the vessel. Analysis of the data is provided and problems identified along the fruit export cold chain are discussed. This article concludes by highlighting areas that need to be addressed along the fruit export supply chain.

\section{Theoretical perspective}

The optimal management of cold chains is important. Effective cold chain management begins on the farm and ends in the refrigerator at home (Jobling n.d.). A study by the University of KwaZulu-Natal found that the quality of avocados is severely affected by breaking the cold chain. The results of this study estimate that $80 \%$ of fruit stored at the appropriate temperature without a break in the cold chain maintained its quality, whilst only $31 \%-60 \%$ of fruit which had a cold chain break achieved the same quality levels (Blakey, Bower \& Bertling 2011; also see Freiboth et al. 2013). The most effective methods of slowing quality loss in fruit are controlling the product temperature and reducing the amount of time that the product is at less-thanoptimal temperatures (Thompson, Mitchel \& Kasmire 2011). Wageningen UR Food and Biobased Research investigated a number of preservation techniques for maintaining the quality of fruit and vegetables. They found temperature control and a closed cold chain to be the most important techniques (Montsma 2012).

Several studies have been conducted to analyse different aspects of the South African fruit export industry from diverse disciplines (Baetsen 2014; Commonwealth Secretariat 2008; Freiboth 2012; Haasbroek 2013; Ntombela \& Moobi 2013; Ortmann 2005; Van Dyk \& Maspero 2004). There are also studies and reports that confirm the negative effects of breaks in the cold chain on perishable products, as well as protocols regarding the handling of these products in the cold chain (M. Dodd, pers. comm., 13 July 2013; Freiboth 2012; Haasbroek 2013; Ngcobo 2008, 2012). Yet, losses still occur. It is therefore important to identify the causes of the temperature breaks along the fruit export cold chain so that industry can take steps to overcome the problems. The theoretical perspective section of this article starts by giving a brief overview of the South African fruit export cold chain. Next, it identifies factors that affect the quality of fruit. It then discusses the role of the PPECB in the export cold chain and it ends off by discussing the NAVIS and Refcon systems implemented in the Port of Cape Town.

\section{The South African fruit export cold chain}

The South African fruit export cold chain consists of many steps and role-players. For the purposes of this article, the fruit export cold chain is explained from the point of harvesting to the port. 
The first step in the fruit export supply chain is the harvesting of the fruit in the orchards or vineyards. After harvesting, the fruit is sent to pre-cooling. Pre-cooling is a process through which the fruit is cooled down rapidly to remove 'field heat' from the fruit as quickly as possible after the fruit has been harvested. Pre-cooling is essential to slow down the deterioration process. After the fruit has been pre-cooled the fruit is packaged and placed in a cold store facility. When the refrigerated container arrives at the cold store, the pallets of fruit are removed from the cold store and usually staged outside under cover in the order that they have to be loaded. The container cannot be precooled as condensation will form inside the container when the doors are opened and this will negatively impact the quality of the fruit. Once the fruit has been loaded into the refrigerated container, it can be transported to the port (Freiboth et al. 2013).

The refrigerated container is powered by electricity and needs to be connected to a power source at all times. When the container is transported by truck, a generator set (commonly known as a genset) is used for trips longer than two hours. A genset generates electricity via a diesel engine. The genset uses a separate engine from that of the truck and is usually located under the framework of the truck trailer that carries the container (Stander 2014).

There are certain differences between the fruit export cold chains of different types of fruit. Apples, pears and plums are first pre-cooled and kept in a cold store before being packed for export. However, grapes are pre-cooled and packed before being placed in a cold store. These different handling processes could result in different cold chain issues. Once the fruit has been loaded into a refrigerated container to be transported to the port, the cold chain for all fruit types is the same (Freiboth et al. 2013).

On arrival at the port, the container is offloaded from the truck and transported to a specific location in the reefer stack where the container is plugged in and monitored to retain its optimum temperature. The reefer stack is the area in the port allocated specifically for reefer containers. The area is equipped with a power source for each reefer container entering the stack. Once the container is placed in its specific location in the stack, the container is plugged into the power source of the stack and the temperature of the reefer container is monitored throughout its stay in the stack (Haasbroek 2013).

\section{Factors affecting the quality of fruit}

Fruit is classified as a living object and once harvested steps need to be taken to maximise the shelf life of the fruit. Fruit starts to deteriorate in terms of quality and freshness as soon as it is picked, and will inevitably rot (Jobling n.d.). Consequently, it is essential to provide effective postharvest management and cold chain maintenance in order to extend the lifespan of the fruit as much as possible (Haasbroek 2013). According to Jobling (2002), the most important factor in postharvest management is temperature management. Temperature management is important for two reasons, namely the impact that it has on the rate of respiration of the fruit as well as its impact on the growth rate of postharvest micro-organisms (Jobling n.d.). In addition, fruit quality is also impacted by relative humidity, the cooling of fruit in pre-coolers and cold stores and the proper cooling of fruit in reefer containers.

\section{Rate of respiration}

Respiration in fruit is a chemical process where the fruit converts sugars and oxygen into carbon dioxide, water and heat (Becker \& Fricke n.d.). Temperature has a direct influence on the fruit's respiration rate. A rise in temperature will cause the respiration rate to rise, which will result in the fresh fruit deteriorating faster (Jobling n.d.). Thus, a higher respiration rate results in a shorter shelf life as illustrated in Figure 1.

It is important to note that different fruit types respire at different rates at a constant temperature.

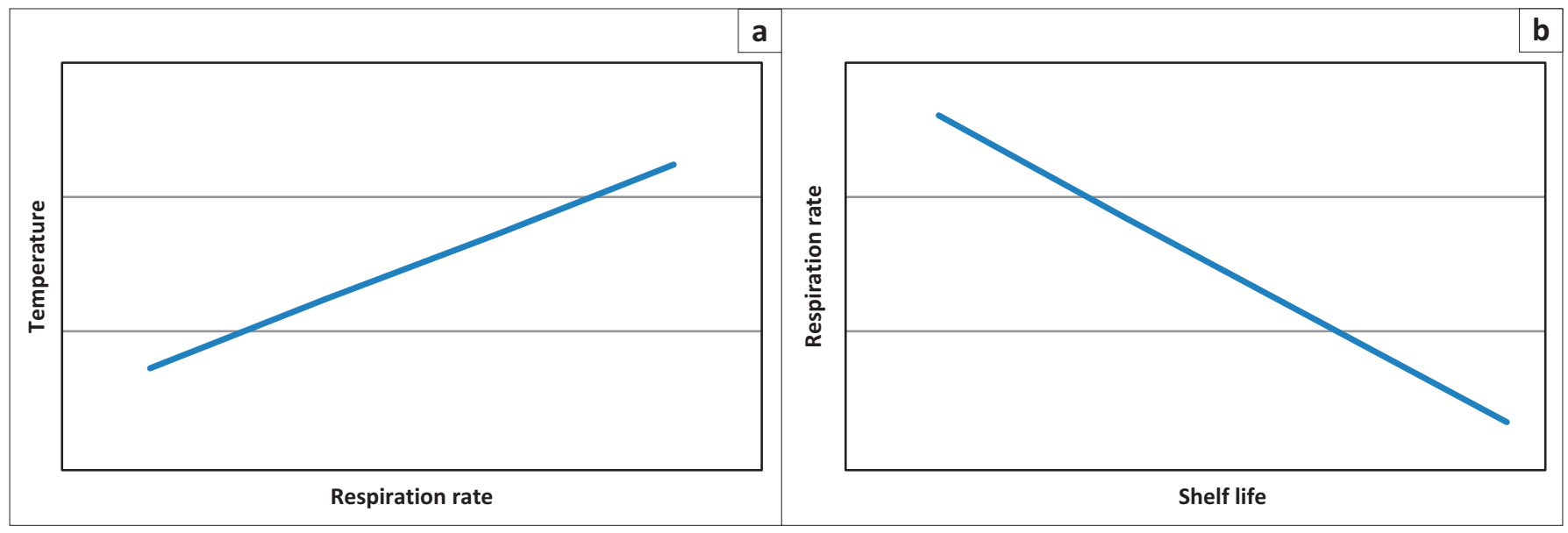

Source: Nelson, K.E., 1985, Harvesting and handling California grapes for market, UC Bulletin 1913, ANR Publications, Oakland, CA, p. 42

FIGURE 1: Relationship of respiration rate with that of temperature and shelf life. (a) Effect of temperature on respiration rate and (b) effect of respiration rate on shelf life. 
Fruit continues to respire throughout its postharvest life and therefore it is critical to transport and store the fruit at their optimal temperatures as prescribed by the PPECB throughout the cold chain to keep the respiration rate as low as possible and in so doing to extend the shelf life of the fruit. Each fruit variety has its own specific temperature, which must be maintained to maximise its shelf life. For the majority of fruit cultivars, this varies between $-0.5{ }^{\circ} \mathrm{C}$ and $15{ }^{\circ} \mathrm{C}$ (PPECB 2013). It is critical that all role-players along the cold chain are aware of these optimum temperatures per fruit type and follow the relevant PPECB protocols closely.

\section{Growth rate of postharvest micro-organisms}

Fruit is vulnerable to diseases caused by a large range of bacteria and fungi. In general, fruit tends to be more prone to fungal diseases than bacterial ones, because fruit normally contains high acid levels, which makes them resistant to bacteria. However, as the fruit ripens this resistance decreases as ripe fruit has lower acid levels, softer skin, higher sugar levels and weaker natural defence barriers (Jobling n.d.). The growth rate of both bacteria and fungi increases with a rise in temperature. In some cases, particularly for soft fruit cultivars, there is no chemical treatment available and temperature management is the only tool available for preventing postharvest rots and the growth of postharvest micro-organisms (Jobling n.d.).

\section{Relative humidity}

Another process that continues after harvesting is transpiration, that is, the loss of water by evaporation. This results in the deterioration of appearance, a reduction in nutritive quality and a loss of weight in the fruit. As a result, maintaining an optimum level of relative humidity during the storage and transport of fresh fruit is important. However, its importance is often underestimated and, therefore, humidity control is neglected. It is essential for role-players in the fresh fruit cold chain to understand the benefits of maintaining optimum relative humidity levels in order to lengthen the shelf life of the fruit and to maximise fruit quality (Jobling n.d.).

\section{Cooling of the fruit in pre-coolers and cold stores}

It is vital to remove field heat from grapes and apples as soon as possible after harvest. This decreases their respiration rate and also slows down the growth of contaminating microorganisms. Failure to remove the field heat can result in the accumulation of high concentrations of carbon dioxide and rapid temperature rises, which can have a negative effect on the quality of the fresh produce. An alternative method is to harvest the fruit early in the morning when it is still cool (Practical Action 2012).

\section{Cooling of the fruit in containers}

According to Hamburg Süd (n.d.), reefer containers are designed to maintain specific temperatures (in a given range) for the cargo that they are carrying and not to cool the cargo down further. This concept is supported by Rodrigue and Notteboom (2013) who state that cold chain devices are designed to maintain a temperature, but not to bring a shipment to a specific temperature, so they are unable to perform adequately if a shipment is not properly prepared and conditioned. Therefore, it is essential that the fruit must be properly cooled to its optimal storage temperature prior to being loaded into the container.

When the fruit is loaded into containers at higher temperatures the respiration rate and risk of fungal growth will increase as described above.

\section{The role of the Perishable Products Exports Control Board in the export cold chain}

The PPECB was established by an act of parliament in 1926 (De Beer, Paterson \& Olivier 2003). The PPECB is an independent South African service provider of quality certification and cold chain management services for producers and exporters of perishable food products. The PPECB essentially controls all exports of perishable products from South Africa. The exports have a monetary value of approximately R20 billion per year (PPECB 2013).

The PPECB ensures that all perishable products that are destined for export satisfy internationally accepted quality levels. The PPECB protocols and procedural guidelines are published annually in their Blue Book, and contain important guidelines for the handling, storage and transportation of perishable products, with specific emphasis on the optimum temperature of each product (also see Freiboth et al. 2013).

\section{The NAVIS and Refcon systems}

The logistical operations of containers at the Port of Cape Town are supported by the NAVIS and Refcon systems. The NAVIS SPARCS is a Web-based terminal operating system that was developed to manage the movement of all container logistics and operations. NAVIS is fully operational in 21 marine and rail terminals across South Africa, including the Port of Cape Town.

The NAVIS system enables the monitoring of cargo along land transport routes in South Africa and the movement of cargo through the different container terminals. When the container is checked in at the port gate, the NAVIS system assigns a place for the container in the container yard according to when the container is required to be loaded on the vessel. The system offers cargo-related information from the time the cargo enters the port gate. It provides information from the port gate to the yard, from the yard to the vessel and vice versa (E. Salasa, pers. comm., 08 June 2012). Clients can interact with the system through a customer access portal, which enhances visibility for each link along the supply chain (Transnet 2013). By centrally coordinating the operations in the container terminal, the ability to identify and locate containers is greatly improved. This results in a smoother operation when the container is loaded out at a later stage, reducing the chance of breaks in the cold chain whilst the 
container is inside the port. Other benefits provided by the NAVIS system include a paperless system, which could help to eliminate costly errors, through streamlined planning and scheduling. In addition, the NAVIS system provides real-time tracking and increased efficiency in managing and filling stockyard space (Haasbroek 2013).

In the Port of Cape Town, the NAVIS system works together with the Refcon system to support the efficient operations of reefer containers. Whilst the NAVIS system offers realtime tracking of all cargo, the Refcon system remotely monitors the state of reefer containers whilst they are stored in the container yard and whilst they are loaded on board a container ship. The Port of Cape Town has recently installed the Refcon (Version 6) system successfully.

The Refcon reefer monitoring system is a computer program which allows complete visibility of the status of reefer containers in the stack yard of a port. Before the installation of the Refcon system at the Port of Cape Town in January 2013, reefer containers had to be manually checked by employees on a continuous basis. This made it difficult to monitor the functionality of each reefer container in the yard simultaneously, which resulted in delayed problem acknowledgement and repair of faulty reefers. With the implementation of the Refcon system, it is possible for port operators to view the functionality of all reefer containers on their computer screens simultaneously. The status of each container is illustrated by the colour of the container depicted on the screen. For example, when the colour of the container on the screen is green, it means that the reefer container is operating well and is at the right temperature. When the container is flashing red, it means that new alarms have been identified and a static red container means that the alarms have been acknowledged (E. Salasa, pers. comm., 08 June 2012). A container represented on the screen in blue with a grey circle means that operations are in progress to fix alarming situations on that specific reefer (Emerson Climate Technologies 2012). The Refcon system helps with the operations of reefer containers inside the container terminal. In addition, the Refcon system can identify problems with reefers immediately and allows them to be addressed appropriately.

There are numerous benefits provided by the Refcon system to the logistics operations at a port. The NAVIS and Refcon systems are used in combination to monitor the container temperatures and send out alerts if the container is unplugged for more than a specified time, or if the container temperature moves outside the prescribed range. This allows the quality of the cargo inside the reefer containers to be preserved better as the system alerts the user about any problem with the reefer container before potential cargo damage occurs.

\section{Research method and design}

The growing and picking stages on the farm play an important role in the final quality of the product. However, this article specifically looks at breaks in the cold chain and analyses the fruit export supply chain from the cold store to the port. The investigation only starts from the point in the supply chain where the fruit is cooled or about to be cooled due to the importance of removing field heat from the fruit as quickly as possible. The investigation ends once the container is loaded onto the ship, due to practical reasons. Retrieving data from the overseas receiver can be problematic - especially in terms of language barriers when the shipment is destined for regions such as the Far East or Russia. The article focuses on the South Africa to Europe fruit export supply chain. This is because it is the most accessible region in terms of retrieving the temperature data and getting comprehensive quality reports as South African fruit exporters have a close relationship with their associates in Europe. Types of fruit studied include grapes, plums, pears and apples as the quality of these fruit types is impacted significantly by temperature breaks in the cold chain.

The study was conducted over a two-year period. Data were collected during the summer fruit seasons of 2011/2012 and 2012/2013 (before and after the implementation of the NAVIS and Refcon systems). Quantitative data were gathered in two forms during this study. Firstly, temperature trials were conducted during the 2011/2012 and 2012/2013 summer fruit seasons. Secondly, temperature data were collected from exporting companies who monitor the temperature of the fruit that they export from South Africa. Both data sets were collected for fruit from different production areas in the Western Cape and Northern Cape exported through the Port of Cape Town. Mainly the latter data set is used for this article.

The first year analysed data from the 2011/2012 season. This study was an exploratory study and helped to find the main causes of breaks along the cold chain. It also helped to identify areas where more detailed research was needed which guided the research design during the second year of research. The second year of research examined data collected from the $2012 / 2013$ season. It provides a more in-depth analysis of the temperature breaks along the cold chain.

The article focuses on information from a data sample of four of the top ten fruit exporting companies (which represented $56 \%$ of the fruit exports for the four fruit types that were studied). Due to ethical permission requirements, the data of individual companies are treated as confidential and only the combined results are revealed.

\section{Data collection}

To determine the impact of temperature breaks on the quality of fruit, it was important to monitor the temperature of the fruit along the supply chain from when the fruit is loaded into a container at a cold store to the port. The quality of the fruit after it arrived at its destination could then be compared to the temperature information collected along the supply chain and any relationships between breaks in temperature and final quality could be identified. The data analysis took 
five factors into consideration. Firstly, location in the supply was classified to determine where temperature breaks are occurring along the supply chain. Secondly, the temperature was measured to ascertain whether a break in the cold chain had occurred or not. Thirdly, the lengths of temperature breaks were identified to establish the impact that the length of a temperature break has on the final quality of the fruit. Fourthly, the relative humidity inside a container was measured during the trials to determine the overall impact of relative humidity on the final quality of fruit and, finally, the quality of fruit was established by verifying whether there were quality claims linked to a specific container of fruit.

The PPECB requires at least hourly readings of the temperature inside a container during the fruit export process (PPECB 2013). Temperatures are logged using temperature monitoring devices such as TempTale ${ }^{\circledR}$ monitors or iButtons ${ }^{\circledR}$, which capture the ambient temperature in a container at preset intervals for the duration of the shipment. The monitors are inserted into a carton of fruit - usually in the pallet closest to the door - just before the container is sealed. Once the container is opened at the final destination, the temperature data are captured, either by manual download from the device or transmission via radiofrequency identification (RFID) technology, and then sent to the exporter (also see Freiboth et al. 2013).

Loggers that additionally record relative humidity, as well as probes that record core fruit temperature, are also available. Unfortunately, these types of loggers are considerably more expensive than the normal temperature loggers and are not required in most markets. As a result, they are not usually inserted into containers, unless the intended market specifically requires that they are used in addition to the normal temperature loggers (also see Freiboth et al. 2013). These relative humidity and core temperature loggers do, however, add considerable value to the data captured. Relative humidity loggers and core temperature loggers were used in the trial studies.

Some importers only send the temperature information and the quality report of a shipment if there is a quality claim involved, unless the exporter specifically requires the information for their own records (also see Freiboth et al. 2013). As a result, a portion of the available historic data is for shipments that resulted in claims. The article examines temperature data from the 2011/2012 and 2012/2013 export seasons.

By adding location information to the temperature time series, an analysis of the different sections of the fruit export supply chain could be done to determine in which sections breaks occur. Four main phases between the pack house and the port were identified for the fruit export supply chain: firstly, the interface between the cold store and the truck, secondly, the transport leg from the cold store to the port, thirdly, the time spent in the port (plugged into the stack) and, finally, when the fruit is removed from the stack and loaded onto the vessel. Phase 1 and Phase 2 were examined to determine the time it takes for the fruit to move from the cold store to the port. Phase 3 and Phase 4 were examined to determine the average amount of time that a container spends inside the port. Most importantly, the temperature was examined to determine whether there are any considerable breaks in the cold chain during these four phases. Comparison was then made between the 2011/2012 and 2012/2013 fruit seasons (before and after implementation of the NAVIS and Refcon systems) to determine whether the implementation of the NAVIS and Refcon systems in the Port of Cape Town had made any difference to the number of breaks experienced in the fruit export cold chain.

The temperature information was collected from fruit exporters who agreed to share their data for analysis. The analysis was conducted using Microsoft Excel and the results are depicted in the form of graphs.

\section{Results and discussion}

To help determine the impact of breaks in temperature on the final quality of fruit, this article evaluates data that were gathered during the summer fruit seasons of 2011/2012 and 2012/2013 (before and after implementation of the NAVIS and Refcon systems). For the purposes of this article a break in the fruit cold chain was defined as 'any time in the data where the ambient temperature of the air measured within the fruit container rose above $2{ }^{\circ} \mathrm{C}$ for longer than 90 minutes'. The optimal storage temperature (pulp temperature) for the fruit types studied is $-0.5^{\circ} \mathrm{C}$ for table grapes, $-1.5^{\circ} \mathrm{C}$ for summer pears, $-0.5{ }^{\circ} \mathrm{C}$ for apples and $-0.5{ }^{\circ} \mathrm{C}$ for plums in most cases (although it varies according to cultivar and voyage). Two separate data sets were analysed. The first set of data examined a total of 196 containers exported from South Africa during the 2011/2012 season, whilst for the second set of data, temperature data was analysed for a total of 123 containers exported from South Africa during the 2012/2013 season.

Figure 2 shows the number of breaks that occurred for each of the 196 containers examined in the 2011/2012 season. Only

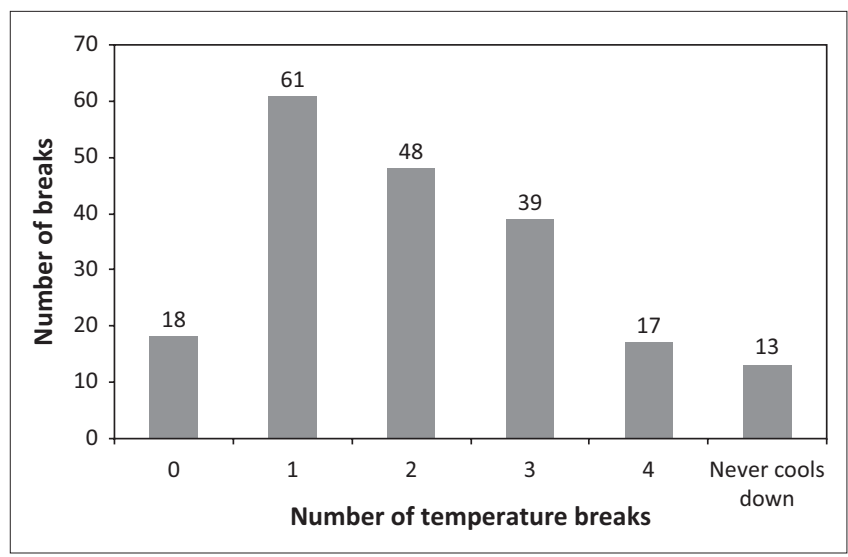

Source: Freiboth, H.W., 2012, Investigating temperature breaks in the summer fruit export cold chain: A case study, unpublished master's assignment, Dept. of Logistics, Stellenbosch University, Stellenbosch

$n=196$.

FIGURE 2: Number of breaks in the cold chain during the $2011 / 2012$ season. 


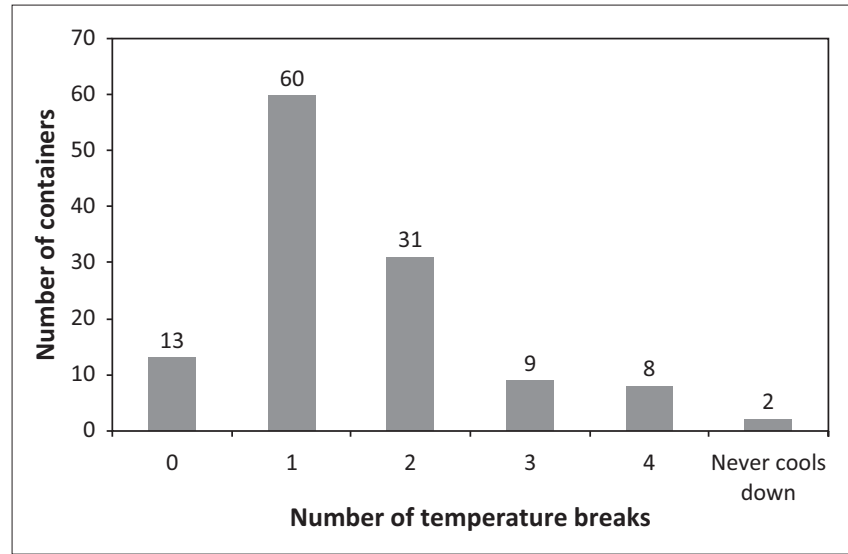

Source: Haasbroek, L.M., 2013, An analysis of temperature breaks in the summer fruit export cold chain from pack house to vessel, master's thesis, Dept. of Logistics, Stellenbosch University, Stellenbosch

$n=123$.

FIGURE 3: Number of breaks in the cold chain during the $2012 / 2013$ season.

18 of the containers (or 9.2\%) had no breaks. Sixty-one (31.1\%) of the containers had one break, $48(24.5 \%)$ of the containers experienced two breaks, $39(19.9 \%)$ of the containers had three breaks and 17 (8.7\%) of the containers experienced four breaks.

For the data analysis conducted during the 2011/2012 season, the main focus was on identifying the leading causes of breaks along the cold chain. The analysis was also used to pinpoint areas that needed to be investigated in more detail and subsequently resulted in a more in-depth analysis during the 2012/2013 season.

Figure 3 illustrates the number of breaks that transpired for each of the 123 containers analysed in the 2012/2013 season. Only 13 of the containers (which is equivalent to $11 \%$ ) had no breaks. The majority of the containers (49\%) experienced one break throughout the data set. However, it should be noted that although a large portion of the containers had only one break, many of these breaks continued for longer than a day. A further $25 \%$ of the containers had two cold chain breaks throughout the data set. The majority of these breaks occurred during the truck-to-port interface. There were nine containers (7.3\%) that had three cold chain breaks and eight containers (6.5\%) with four breaks each. There were also two containers for which the ambient temperature of the container never dropped below $2{ }^{\circ} \mathrm{C}$ throughout the whole data set.

Figure 2 and Figure 3, therefore, highlight the fact that in both cases there are a disturbing number of breaks in the cold chain, which confirms the fruit industry's concerns that a reason for the loss in fruit quality being experienced is linked to temperature breaks along the cold chain.

Figure 4 shows the number of breaks that originated in the respective cold chain segments during the 2011/2012 season. For the purpose of this article, the truck segment is represented by the time that elapses from when the fruit pallets are loaded into the container up to the point where the truck enters the port gate. One hundred and four of the breaks

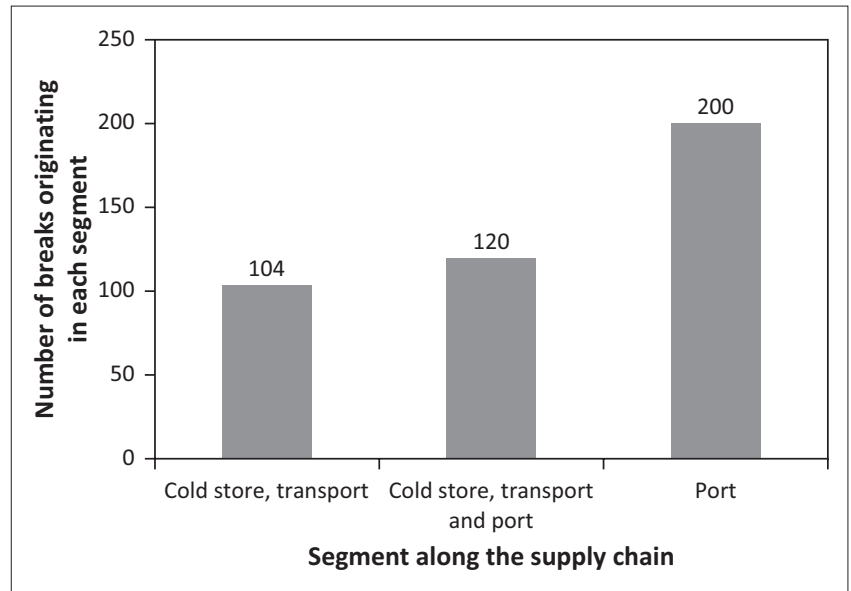

Source: Freiboth, H.W., 2012, Investigating temperature breaks in the summer fruit export cold chain: A case study, unpublished master's assignment, Dept. of Logistics, Stellenbosch University, Stellenbosch

$n=424$.

FIGURE 4: Number of breaks originating in respective cold chain segments of the $2011 / 2012$ season.

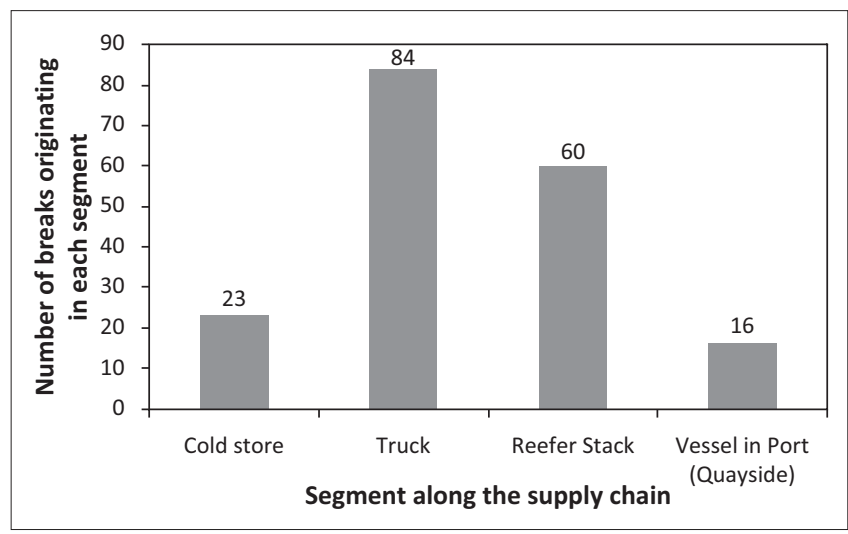

Source: Haasbroek, L.M., 2013, An analysis of temperature breaks in the summer fruit export cold chain from pack house to vessel, master's thesis, Dept. of Logistics, Stellenbosch University, Stellenbosch

$n=183$.

FIGURE 5: Number of breaks originating in respective cold chain segments of the $2012 / 2013$ season.

(or $24.5 \%$ ) originated at the interface between the cold store and the truck (when the pallets are loaded into the container) and cooled down before entering the port. One hundred and twenty of the breaks (equivalent to $28.3 \%$ ) started at the interface between the cold store and the truck, but only cooled down properly once they had been plugged into the stack in the port. Two hundred of the breaks (or $47.17 \%$ ) originated in the port whilst the containers were waiting to be plugged into the reefer stacks or when the containers were loaded onto the vessels. From these results, it is clear that prior to the implementation of the NAVIS and Refcon systems, $47.17 \%$ of the breaks originated in the port.

During the following year (season 2012/2013), Figure 5 shows that the majority of the breaks in the cold chain data originated in the truck segment of the cold chain, as it is responsible for 84 of the 183 breaks (45.9\%) identified. A large portion of the breaks (almost every break) identified in the truck segment occurred at the start of the truck data, which means that the main problem area along the cold chain 
is the interface between the cold store and where the fruit is loaded into containers for the truck segment.

The reefer stack segment of the cold chain was identified as having the second highest number of breaks originating in the segment, with a total of 60 breaks. The reefer stack segment (according to the definition used for this article), includes the time from the moment when the truck enters the port gate (gate entry time at port) up to the point where the reefer container is loaded onto the vessel (vessel loading time). It is, therefore, mainly the time that the container spends in the reefer stack. Figure 5 shows that $32.8 \%$ of the breaks identified originated during this segment, which is a substantial decrease in breaks originating in the port following the implementation of the NAVIS and Refcon systems.

The cold store and vessel segments together only accounted for the origin of $21.3 \%$ of the breaks identified in the 2012/2013 season. The cold store segment is defined as:

the time from the moment that the ambient logger is inserted into a fruit pallet at the cold store up to the moment just before the pallets are loaded into the reefer container for transport to the port. (Haasbroek 2013)

Although Figure 5 shows that only 23 of the 183 breaks in the $2012 / 2013$ season $(12.6 \%)$ originated in the cold store, this figure might be misleadingly low as only a small percentage of the data (30\%) in the 2012/2013 season included temperature data for this segment. The majority of the data $(70 \%)$ only started at the truck segment. It is important to note that the breaks in the cold store segment and those in the truck segment of the 2012/2013 season actually represent the same type of breaks. These are breaks that originate when the fruit is removed from the cold store to be loaded into a truck and it makes contact with the warmer outside temperature. There are only a few cases where breaks actually occur whilst the fruit is still inside the cold store (three cases were detected during the 2012/2013 season).

For the purposes of this article the vessel segment only includes the time from the moment the container is loaded onto the vessel (vessel loading time) up to the point where the vessel sails out of the port (vessel departure time). Temperature data for the deep-sea voyage is therefore not included, because it was not always possible to get a hold of the vessel departure times for all containers. In these cases, the data was cut off 48 hours after the container had been loaded onto the ship. Figure 5 shows that only 16 of the breaks $(8.7 \%)$ originated during this time.

\section{Conclusion}

From the data analysis it is clear that a large number of breaks are experienced along South Africa's fruit export cold chain (of the 196 containers analysed in the 2011/2012 season, 424 breaks in the cold chain were detected and of the 123 containers analysed in the 2012/2013 season, 183 breaks were detected). In addition, it is also evident that a large portion of the breaks originated at the interface between the cold store and the truck ( 224 or $52 \%$ for the $2011 / 2012$ season and 107 or $58 \%$ for the $2012 / 2013$ season). Also, only 18 (or $9.2 \%$ ) of the containers from the $2011 / 2012$ season experienced no breaks along the cold chain and only 13 (or 11\%) of the containers from the 2012/2013 season did not suffer from any breaks along the cold chain. Therefore, it is evident that there are problems with the logistics activities along South Africa's fruit export cold chain and it confirms the fruit industry's concerns that a major cause of the poor quality of fruit that is currently being experienced is linked to breaks along the cold chain.

It is also evident that there has been an improvement in the number of breaks experienced in the Port of Cape Town following the implementation of the NAVIS and Refcon systems. Prior to the application of the systems $47.17 \%$ of the breaks originated in the port, whilst post application $41.5 \%$ originated in the port $(32.8 \%$ in the reefer stack and $8.7 \%$ when the fruit is being loaded onto the vessel). However, although there have been improvements made in the port, there are still too many breaks occurring in this leg of the supply chain.

The results of the study were presented to the exporters and cold stores that assisted with the investigation to alert them about the breaks during loading of the containers at the cold stores and during handling at the port. It was recommended that airlocks be installed at the cold stores to eliminate the breaks. However, this would require building new loading bays at many cold stores, which would be costly, especially since the cold stores are only used during the fruit export season. A further study was proposed to investigate the causes of temperature breaks inside the container terminal at the Port of Cape Town.

Although this article has addressed a range of issues, there are other areas that can be researched further in the future. A simulation model has been developed by Aiello et al. (2012), which determines how the shelf life of fruit is impacted by temperature changes during each segment of the cold chain. This kind of sensitivity analysis could be useful if it is recognised during a shipment that a certain segment of the cold chain has been compromised. The exporter could then adjust the expected shelf life of the product and give advance warning to the receiver that the specific consignment should be sold as soon as possible. It would also be valuable to expand the analysis of the supply chain to include the segments from the farm to the pack house, the sea leg and from the port of destination to the retailer.

Fruit export companies that are willing to help could be asked to capture the data of shipments as soon as it becomes available. To protect the identities of participating companies, codes would be used instead of the real company names. Data for fruit shipments during both summer and winter could be captured to compare the impact of seasonality on the cold chain. By following this approach, more reliable data could be collected since it would be 
captured as soon as it becomes available. This would result in a more comprehensive analysis of the problem areas of the fruit export cold chain.

The fruit industry plays an important role in the South African economy and therefore it is essential that it continues to be successful. However, the international fruit market is becoming increasingly competitive and this is putting pressure on exporters to improve the quality of the fruit that they produce (Ntombela \& Moobi 2013). For the South African fruit industry to continue to be a key player in the international market, it is important that all role-players understand and are properly trained in the importance of maintaining the cold chain at all times and the impact that not adhering to the requirements has on the quality of the fruit.

\section{Acknowledgements}

The research conducted for this article was done with funding by the Postharvest Innovation fund along with co-funding from the Council for Scientific and Industrial Research (CSIR) and Stellenbosch University.

\section{Competing interests}

The authors declare that they have no financial or personal relationships that may have inappropriately influenced them in writing this article.

\section{Authors' contributions}

L.L.G-G. (Stellenbosch University) acted as the supervisor for both students during their master's degrees. She also wrote the article from the research conducted. L.H. (Stellenbosch University) conducted the research from the 2012/2013 season for her master's degree. H.F. (Stellenbosch University) conducted the research from the 2011/2012 season for his master's degree. F.E.v.D. (CSIR) was the project leader on the project for which the research was conducted and acted as co-supervisor for both students during their master's degrees.

\section{References}

Aiello, G., La Scalia, G. \& Micale, R., 2012, 'Simulation analysis of cold chain performance based on time-temperature data', Production Planning \& Control 23(6), 468-476. http://dx.doi.org/10.1080/09537287.2011.564219

Baetsen, S., 2014, Post-Harvest Innovation Programme, viewed 05 February 2014 from http://www.postharvestinnovation.org.za/projects-2/scrutinising-southafrican-fresh-fruit-export-logistics/

Becker, B.R. \& Fricke, B.A. n.d., Transpiration and respiration in fruits and vegetables, viewed 05 July 2013, from http://b.web.umkc.edu/beckerb/publications/chapters/ trans resp.pd

Blakey, R.J., Bower, J.P. \& Bertling, I., 2011, 'Importance of cold chain maintenance and storage temperature to avocado ripening and quality', Acta Hort (ISHS) 911, 555-564.
Commonwealth Secretariat, 2008, Logistics \& cold chain study (From SA pack house to $S A$ port), s.l., s.n.

De Beer, G., Paterson, A. \& Olivier, H., 2003, 160 years of export - The history of the Perishable Products Export Control Board, The Perishable Products Export Control Board, Parow.

Emerson Climate Technologies, 2012, REFCON 6: The safest way to transport refrigerated cargo, viewed 06 July 2013, from http://www.emersonclimate.com/ en-us/products/container_monitoring/documents/product_leaflets/refcon6 -web.pdf

Food and Agriculture Organization of the United Nations, 2011, Global food losses and food waste - Extent, causes and prevention, United Nations, Rome.

Freiboth, H.W., 2012, Investigating temperature breaks in the summer fruit export cold chain: A case study, unpublished master's assignment, Dept. of Logistics, Stellenbosch University, Stellenbosch.

Freiboth, H.W., Goedhals-Gerber, L.L., Van Dyk, F.E. \& Dodd, M.C., 2013, 'Investigating temperature breaks in the summer fruit export cold chain: A case study', Journal of Transport and Supply Chain Management 7(1), 7 pages. http://dx.doi. org/10.4102/jtscm.v7i1.99

Haasbroek, L.M., 2013, An analysis of temperature breaks in the summer fruit export cold chain from pack house to vessel, master's thesis, Dept. of Logistics, Stellenbosch University, Stellenbosch.

Hamburg Süd n.d., Unbroken cold supply chain for perishables, viewed 06 February 2014, from http://www.hamburgsud-line.com/hsdg/en/hsdg/reefer 7/cargo care_1/temperature control_1/temperature control.jsp

Intelliflex, 2012, Temperature management and the cold supply chain: Improving quality shelf-life and revenues with pallet-level monitoring of fresh produce, viewed 17 February 2014, from http://www.rfid24-7.com/wp-content/uploads/ 2012/07/INTELLEFLEX-TemperatureManagementCold-Chain.pdf

Jobling, J., 2002, Postharvest management of fruit and vegetables, viewed 03 June 2013, from http://www.postharvest.com.au/postharvest.pdf

Jobling, J. n.d., Correct cool chain management is essential for all fruit and vegetables, viewed 03 June 2013, from http://www.postharvest.com.au/Shelflife.PDF

Montsma, M.P., 2012, Conditioning techniques for the multimodal fruit and vegetable chains, viewed 14 March 2014, from https://www.wageningenur.nl/en/show/ Temperature-control-and-closed-cold-chain-most-important-preservationmethods-for-fruit-and-vegetable-produce.htm

Nelson, K.E., 1985, Harvesting and handling California grapes for market, UC Bulletin 1913, ANR Publications, Oakland, CA.

Ngcobo, M.E.K., 2008, Cooling and shipping studies on table grapes, master's thesis, Dept. of Horticulture, Stellenbosch University, Stellenbosch.

Ngcobo, M.E.K., 2012, Post-harvest cold chain R\&D, PPECB, Cape Town.

Ntombela, S. \& Moobi, M., 2013, South African fruit trade flow; January 2013, Market and Economic Research Centre, Pretoria.

Ogunleye, R.F. \& Adefemi, S.O., 2007, 'Evaluation of the dust and methanol extracts of Garcinia kolae for the control of Callosobruchus maculatus (F.) and Sitophilus zeamais (Mots)', Journal of Zhejiang University SCIENCE B 8(12), 912-916. http:// dx.doi.org/10.1631/jzus.2007.B0912

Ortmann, F.G., 2005, Modelling the South African fresh fruit export supply chain master's thesis, Dept. of Applied Mathematics, Stellenbosch University, Stellenbosch.

Postharvest Innovation Programme, 2013, Research study brief, Postharvets Innovation Programme, Cape Town.

PPECB, 2013, Cold chain management, viewed 03 June 2013, from http://www.ppecb. com/index.php/cold-chain-management.htm

Practical Action, 2012, Cold storage of fruits and vegetables, viewed 14 September 2013, from http://practicalaction.org/page/docs/technical_information_service/ cold_storage_fruits_vegetables.pdf

Rodrigue, J-P. \& Notteboom, T., 2013, The cold chain and its logistics, viewed 23 January 2014, from http://people.hofstra.edu/geotrans/eng/ch5en/appl5en/ ch5a5en.html

Stander, C., 2014, The handling of fruit reefer containers in the Cape Town Container Terminal, master's thesis, Dept. of Logistics, Stellenbosch University, Stellenbosch.

Thompson, J.F., Mitchel, E.G. \& Kasmire, R.F., 2011, 'Cooling horticultural commodities', in A.A. Kader (ed.), Postharvest technology of horticulture crops, 3rd edn., pp. 97112, Agriculture and Natural Resources, Publication 3529, University of California, Berkeley.

Transnet, 2013, Transnet, viewed 24 May 2013, from http://www.transnet.net

Van Dyk, F.E. \& Maspero, E., 2004, 'An analysis of the South African fruit logistics infrastructure', ORION 20(1), 55-72. http://dx.doi.org/10.5784/20-1-6 